\title{
THE PREVALENCE OF DRY EYE IN TERTIARY HEALTH CARE CENTER OF ANDHRA PRADESH
}

\author{
Vankadara Naga Suresh ${ }^{* 1}$, Radhika ${ }^{2}$.
}

${ }^{*}$ Professor and Head of the Department of ophthalmology, viswa bharathi medical college, Kurnool, Andhra Pradesh, India.

${ }^{2}$ Associate Professor, Department of ophthalmology, viswa bharathi medical college, Kurnool, Andhra Pradesh, India.

\section{ABSTRACT}

Background: The lack of association between signs and symptoms can affect clinical management of dry eye and increase the difficulty of diagnosis and treatment of dry eye. Hence the purpose of this study is to determine the prevalence of dry eye and evaluate the risk factors associated with it in tertiary health care center of Andhra Pradesh, India.

Materials and Methods: After Informed consent was obtained from a total 100 patients above 20 years of age presenting with various ophthalmic problems to outdoor patient department of Ophthalmology were screened for dry eye. Complete general, ophthalmic history and ocular and systemic examination and by asking dry eye related questionnaires data was collected by the ophthalmologist.

Results: In present study prevalence of dry eye is $48 \%$ which is slightly higher, this is increased progressively with age, male had more prevalence of dry eye than female which is contrast to the most of the previous studies, All of our patients were had dry eye felling $(100 \%)$, sensation $(100 \%)$ presented with red eye $(81.25 \%)$ and watering of eye (72.92\%), with burning sensation (45.83\%), Sticky sensation $(43.75 \%)$, gritty/sandy sensation (41.67\%), Crust on eye lashes (18.75\%), and Stuck shut eye in morning (12.50\%).

Conclusion: The prevalence of dry eye is relatively higher in male and factory workers. Hence they are exposing to the dry hot atmosphere with high temperature.

KEY WORDS: Dry eye, red eye, watering of eye, burning sensation, Sticky sensation, gritty/sandy sensation, and, Crust on eye lashes.

Address for correspondence: Dr. Vankadara Naga Suresh, Professor and Head of the Department of ophthalmology, viswa bharathi medical college, Kurnool, Andhra Pradesh, India.

E-Mail: drnagasuresh@gmail.com

\begin{tabular}{|l|lc|}
\hline \multicolumn{3}{|c|}{ Online Access and Article Informtaion } \\
\hline Quick Response code & \multicolumn{1}{|c|}{ International Journal of Integrative Medical Sciences } \\
& \multicolumn{1}{|c|}{ www.imedsciences.com } \\
\cline { 2 - 3 } & Received: 19-02-2018 & Accepted: 15-03-2018 \\
Dol: 10.16965/ijims.2018.104 & Reviewed: 19-02-2018 & Published: 31-03-2018 \\
\hline Source of Funding: Self & \multicolumn{2}{c|}{ Conflicts of interest: None } \\
\hline
\end{tabular}

\section{BACKGROUND}

A disorder of the tear film due to tear deficiency or excessive evaporation, which causes damage to the interpalpebral ocular surface and is associated with symptoms of ocular discomfort is Dry eye is an under-diagnosed ocular disorder in middle aged and older adults. The prevalence of dry eye varies from $10.8 \%$ to $57.1 \%$. It has been documented that symptoms of dry eye disease do not necessarily reflect the severity of the disease. Reduction in the modifiable risk factors of dry eye is essential to reduce its prevalence [1]. Prevalence varied from $8.4 \%$ in less than 60 yrs to $19.0 \%$ in those older than 80 yrs [2]. Currently, available diagnostic tests do not correlate reliably with symptom severity of dry eye [3]. Prevalence of 1 or more of the 6 dry eye symptoms adjusted for age was $27.5 \%$. After 
adjusting for all significant variables, independent risk factors for dry eye were pterygium and history of current smoking [4].

Standard objective tests for dry eye disease also have short comings. Further diagnosis and assessment of dry eyes are complicated by the considerable variation in the disease symptoms and signs and lack of definitive diagnostic tests. At present there is no 'gold standard' test for developing a clinical diagnosis of dry eye and the patient's self-reported symptoms are a primary element in diagnosis. Because of the general repeatability of symptoms compared with that of diagnostic tests, dry eye has often been considered a symptom based disease. This lack of association between signs and symptoms can affect clinical management of dry eye and increase the difficulty of diagnosis and treatment of dry eye. Hence the purpose of this study is to determine the prevalence of dry eye and evaluate the risk factors associated with it in tertiary health care center of Andhra Pradesh, India.

\section{MATERIALS AND METHODS}

This hospital based cross sectional study was conducted in the department of ophthalmology, viswa bharathi medical college, Kurnool, A.P. Total 100 patients above 20 years of age presenting with various ophthalmic problems to outdoor patient department of Ophthalmology were screened for dry eye. The patients were selected randomly and informed about the nature of study. Patients suffering from acute ocular infections, Increased mucoid discharge and watery secretion suggestive of vkc, Alkali burns, Trachoma, Impaired eyelid function like in bell's palsy, nocturnal lagophthalmos, ectropion, extensive corneal or conjunctival pathology, contact lens users and those who had undergone extra ocular or intra ocular surgery within six months of the screening were excluded. Informed consent was obtained from subjects recruited for the study. Complete general history (including history of systemic diseases, especially related to the dry eye) and ophthalmic history was taken by the ophthalmologist. Also taken ocular and systemic examination and dry eye related questionnaires.
1. Do your eyes ever red?

2. Do your eyes ever feel dry?

3. Do your eyes ever have a burning sensation?

4. Do your eyes ever feel sticky?

5. Do your eyes ever feel watering?

6. Do your eyes ever get stuck in the morning?

7. Do your eyes ever feel a gritty sensation?

8. Do you notice much crusting or discharge on your lashes?

The dry eye test were included Schirmer test, Tear film break up time (TBUT), fluorescein staining of the cornea, slit lamp examination of meibomian glands

\section{Symptoms:}

1 Burning sensation

2 Sandy gritty feeling

3 Foreign body sensation

4Photophobia

5 Heavy lids.

The above symptoms increase in conditions of low humidity and wind.

\section{Clinical signs:}

1. Scanty tear film meniscus over the inferior lid margin

2. Increased debris in the tear film

3. Increase in mucous threads in the inferior fornix.

\section{Diagnosis and Statistical Analysis:}

Positive dry eye symptom was defined as having one or more symptoms often (at least once a week) or all the times. Positive signs were if one or both eyes revealed tear film break up time less than 10 seconds [5], a Schirmer test score less than $5 \mathrm{~min}$ [6] a fluoresce in score more than 1 [6], or the existence of meibomian gland disease which was diagnosed when telangiectasia at the lid margin or plugging of the gland orifices was present (e"grade 1). If three or more than three of the above five were positive, the subject was deemed to be suffering from dry eye. Data were analyzed by using ChiSquare, $Z$ test and strength of association was determined by the odds ratio and significance of Fisher's exact test. P value less than 0.05 was considered statistically significant. 
Table 1: Shows the Dry eyes prevalence (\%) in age groups.

\begin{tabular}{|c|c|c|c|c|c|}
\hline Age group & Frequency & Percent & Dry eyes & $\begin{array}{c}\text { Prevalence } \\
(\%)\end{array}$ & P value* \\
\hline $\mathbf{2 0}-\mathbf{2 9}$ & 7 & 7 & 3 & 42.86 & $<0.05^{*}$ \\
\hline $\mathbf{3 0}-\mathbf{3 9}$ & 10 & 10 & 3 & 30 & $<0.05^{*}$ \\
\hline $\mathbf{4 0}-\mathbf{4 9}$ & 19 & 19 & 5 & 26.32 & $<0.05^{*}$ \\
\hline $\mathbf{5 0}-\mathbf{5 9}$ & 21 & 21 & 10 & 47.62 & $<0.05^{*}$ \\
\hline $\mathbf{6 0}-\mathbf{6 9}$ & 25 & 25 & 12 & 48 & $<0.05^{*}$ \\
\hline $\mathbf{7 0}-\mathbf{7 9}$ & 8 & 8 & 6 & 75 & $<0.05^{*}$ \\
\hline $\mathbf{2 0}$ & 10 & 10 & 9 & 90 & $<0.05^{*}$ \\
\hline Total & 100 & 100 & 48 & 48 & \\
\hline
\end{tabular}

Table 2: Shows the Dry eyes prevalence (\%) in sex groups.

\begin{tabular}{|c|c|c|c|c|c|}
\hline Sex & Frequency & Percent & Dry eyes & $\begin{array}{c}\text { Prevalence } \\
(\%)\end{array}$ & P value* \\
\hline Male & 56 & 56 & 32 & 57.14 & $<0.05^{*}$ \\
\hline Female & 44 & 44 & 16 & 36.36 & $<0.05^{*}$ \\
\hline Total & 100 & 100 & 111 & 48 & \\
\hline
\end{tabular}

Table 3: Shows the Dry eyes prevalence (\%) in occupation.

\begin{tabular}{|c|c|c|c|c|c|}
\hline Occupation & Frequency & Percent & Dry eyes & $\begin{array}{c}\text { Prevalence } \\
(\%)\end{array}$ & P value* \\
\hline Laborers & 38 & 38 & 21 & 55.26 & $<0.05^{*}$ \\
\hline Home makers & 8 & 8 & 5 & 62.5 & $<0.05^{*}$ \\
\hline Students & 28 & 28 & 10 & 35.71 & $<0.05^{*}$ \\
\hline Factory workers & 10 & 10 & 9 & 90 & $<0.05^{*}$ \\
\hline Office workers & 16 & 16 & 3 & 18.75 & $<0.05^{*}$ \\
\hline
\end{tabular}

Table 4: Shows the Strength of association of smoking, drugs and environmental exposure factors with dry eyes.

\begin{tabular}{|c|c|c|c|c|c|}
\hline & \multicolumn{2}{|c|}{ Non exposed group } & \multicolumn{2}{c|}{ Exposed group } & \multirow{2}{*}{ P-value } \\
\cline { 2 - 5 } & $\begin{array}{c}\text { Total } \\
\text { subject }\end{array}$ & Dry eyes & $\begin{array}{c}\text { Total } \\
\text { subject }\end{array}$ & Dry eyes & \\
\hline Excessive wind & 94 & 43 & 6 & 3 & $>0.05$ \\
\hline Sunlight/high temp & 71 & 28 & 29 & 17 & $<0.05^{*}$ \\
\hline Air pollution & 93 & 42 & 7 & 3 & $>0.05$ \\
\hline Smoking & 86 & 37 & 14 & 8 & $<0.05^{*}$ \\
\hline Drugs & 93 & 40 & 7 & 5 & $<0.05^{*}$ \\
\hline
\end{tabular}

Table 5: Shows Symptoms among the dry eye cases.

\begin{tabular}{|c|c|c|}
\hline \multirow{2}{*}{ Symptoms } & \multicolumn{2}{|c|}{ Dry eye case } \\
\cline { 2 - 3 } & Yes & $\%$ \\
\hline Dry eye feeling & 48 & 100 \\
\hline Dry eye sensation & 48 & 100 \\
\hline Red rye & 39 & 81.25 \\
\hline Watering eye & 35 & 72.92 \\
\hline Burning sensation & 22 & 45.83 \\
\hline Sticky sensation & 21 & 43.75 \\
\hline Gritty/sandy sensation & 20 & 41.67 \\
\hline Crust on eye lashes & 9 & 18.75 \\
\hline Stuck shut eye in morning & 6 & 12.5 \\
\hline
\end{tabular}

\section{DISCUSSION}

The millions of people worldwide affected by
Dry eye are a major tear deficiency disorder, and which is often overlooked and under diagnosed. Dry eye syndrome also called as dry eye or keratoconjunctivitis sicca is a common disorder of the tear film that affects a significant percentage of the population, especially those older than 40 years of age. Dry eye is caused by decreased tear production, excessive tear evaporation, and an abnormality in the production of mucus or lipids normally found in the tear layer, or a combination of these. Poor production of tears by the lacrimal gland glands may be a result of age, hormonal changes, or various autoimmune diseases, such as primary Sjögren's syndrome, rheumatoid arthritis, or lupus. Evaporative loss of the watery tear layer is usually a result of an insufficient overlying lipid layer [7]. Non-inflamed obstructive meibomian gland dysfunction is another major cause of lipid tear deficiency or evaporative dry eye and has recently attracted attention as a cause of ocular discomfort. Meibomian gland dysfunction the supply of normal lipid, which leads to increased tear evaporation decreased tear stability, loss of lubrication, and damage to the ocular surface epithelium resulting in dry eye [8].

Clinically dry eye can be divided into three stages. In the first stage the patient has symptoms but no signs are present, in the second stage the symptom of first stage along with reversible signs such as small corneal erosions and superficial ulcers, mucous secretion and hyperemia of nasal and temporal bulbar conjunctiva are present. In third stage patient has symptoms and signs of first and second stage along with irreversible signs such as corneal opacity and ulceration which can be lead to sight threatening corneal complications [9].

In present study prevalence of dry eye is $48 \%$ which is slightly higher but fall within this range of previous studies show that prevalence of dry eye varies from $10.8 \%$ to $57.1 \%$ [10]. The different eye diagnostic criteria and different cut off values of objective dry eye tests are the main cause of such vast disparity in dry eye prevalence.

In our study, dry eye prevalence increased progressively with age which is consistent with the finding in other dry eye studies [11-13]. 
According to Mc Carty et al. as the age increases the tear secretion decreases [14].

Our study found that male had more prevalence of dry eye than female which is contrast to the most of the previous studies report a higher prevalence of dry eye in female than male [10, $13,15-18]$. But our results are similar to R.Ranjan et.al. [11]. Since traditionally male are more active in outside work, so they are more exposed to different exposure factors such as sunlight, high temperature, excessive wind. This might be the cause of high prevalence of dry eye in male population in this study.

Exposure to drugs, sunlight/high temperature and smoking were significantly related to dry eye. These have been suggested as risk factors in various studies $[13,15,19]$. Smoking predisposes the eye to tear film instability by its direct irritant action on the eye and represent modifiable risk factors in dry eye causation. A drug too may disrupt one or more component of the tear film causing it to become unstable.

All of our patients were had dry eye felling $(100 \%)$, sensation $(100 \%)$ presented with red eye $(81.25 \%)$ and watering of eye $(72.92 \%)$, with burning sensation (45.83\%), Sticky sensation (43.75\%), gritty/sandy sensation ( $41.67 \%)$, Crust on eye lashes (18.75\%), and Stuck shut eye in morning (12.50\%). in Australia by Mc Carty et al. reported that most of the patients presented with the symptoms of foreign body sensation, discomfort, itching, tearing and photophobia [14].

To help alleviate the dry eye syndrome, certain self-care tips at home may help. Hot compresses and eyelid scrubs/massage with baby shampoo will help by providing a thicker, more stable lipid layer. This is especially helpful if a person has meibomian gland dysfunction, rosacea, or blepharitis. The heat warms up the oil in the oil glands, making it flow more easily; the massaging action helps get the oil out of the glands [5].

Hot compresses are very beneficial to the normal functioning of the eye. For chronic conditions like meibomian gland dysfunction or blepharitis hot compress help in two ways. First, the warm moisture helps loosen up eyelid debris that has collected on the eyelash follicles.
Secondly, hot compresses help the eyelid glands function normally. In meibomian gland dysfunction this is critical and it will help to reduce dry eye symptoms. For more acute conditions like a style or hordeolum, hot compresses helps to increase the blood flow to the eyelid area and help the body's nature process of healing [6].

\section{Management}

1. Tear replacement: Supplementation of tears with the use of tear substitutes is the mainstay of treatment.

2. Tear preservation: This can be done by punctum occlusion. Punctum occlusion can be reversible by using intracanalicular collagen rods, silicone plugs. Permanent punctual occlusion can be done by electrodissection.

3. Meibomian gland dysfunction: This can be treated by oral tetracycline $250 \mathrm{mg}$ twice daily for a period of 4 to 6 weeks and hot compresses.

4. Topical Cyclosporine A $0.05 \%$ : It is an immunomodulator that specifically inhibits $T$ lymphocyte proliferation. Reduction in ocular surface inflammation with increase in goblet cell count was reported in patients on this mode of treatment.

\section{CONCLUSION}

This study of Andhra Pradesh tertiary health care center provided the prevalence of dry eye and its correlation with different risk factors. The prevalence of dry eye is relatively higher in male population, very high prevalence of dry eye in factory workers (90\%). In this region most factories workers are exposing to the dry hot atmosphere with high temperature inside the factories and outside factories atmosphere also hot and high temperature. This may be the explanation for such high prevalence rate of dry eye in factory workers.

\section{REFERENCES}

[1]. Sahai A, Malik P. Dry eye: Prevalence and attributable risk factors in hospital-based population.. Indian J Ophthalmol. 2005;53:87-91.

[2]. Moss SE, Klein R, Klein BEK. Prevalence of and risk factors for dry eye syndrome. Arch Ophthalmol. 2000;118:1264-68.

[3]. Smith, Janine, Nichols, Kelly k, Baldwin, Edward k. Current patterns in the use of diagnostic tests in dry eye evaluation. Cornea 2008;27(6):656-62. 
[4]. Lee AJ, Lee J, Saw SM, Gizzard, Koh D, Widjaja D et al. Prevalence and risk factors associated with dry eye symptoms: A population based study in Indonesia. Br J Ophthalmol. 2002;86:1347-51.

[5]. Manthorpe R., Oxholm P., Prause J.U., Schiodt M. The Copenhagen Criteria for Sjogren's syndrome. Scandinavian Journal of Rheumatology. 1986;61:19-21.

[6]. Danjo, Y. Diagnostic Usefulness and Cutoff Value of Schirmer's 1 Test in the Japanese Diagnostic Criteria of Dry Eye. Graefe's Archive for Clinical and Experimental Ophthalmology. 1997;235:761-6.

[7]. American Academy of Ophthalmology. Dry eye associated problems more common in elderly adults. URL:http://www.geteyesmart.org/eyesmart/diseases/dry-eye.cfm.

[8]. Terry MA. Dry eye in the elderly. Drugs and Aging 2001;18(2):101-7.

[9]. Murube J, Németh J, Höh H, Kaynak-Hekimhan P, Horwath-Winter J, Agarwal A, et al. The Triple Classification of Dry Eye for Practical Clinical Use. Eur J Ophthalmol. 2005;15:660-7.

[10]. Versura P., Cellini, M., Torreggiani A., Profazio V., Bernabini B. and Caramazza R. Dryness Symptoms, Diagnostic Protocol and Therapeutic Management: A Report on 1200 Patients. Ophthalmic Research. 2001;33:221-7.

[11]. Ranjan R., Shukla S.K., Singh C.V., Mishra B.N., Sinha S., Sharma B.D. Prevalence of Dry Eye and Its Association with Various Risk Factors in Rural Setup of Western Uttar Pradesh in a Tertiary Care Hospital. Open Journal of Preventive Medicine. 2016;6;5763.

[12]. Albietz, J.M. Prevalence of Dry Eye Subtypes in Clinical Optometry Practice. Optometry and Vision Science. 200;77:357-63.

[13]. Moss S.E., Klein R., Klein, B.E. Prevalence of and Risk Factors for Dry Eye Syndrome. Archives of Ophthalmology. 2000;118:1264-8.
[14].McCarty, C.A., Bansal, A.K., Livingstone, P.M., Stanislavsky YL, Taylor HR. The Epidemiology of Dry Eye in Melbourne, Australia. Ophthalmology. 1998;105(6);1114-9.

[15]. Hikichi T., Yoshida A., Fukui Y., Hamano T., Ri M., Araki K., et al. Prevalence of Dry Eye in Japanese Eye Centers. Graefes Archive for Clinical and Experimental Ophthalmology. 1995:233:555-8.

[16]. Caffery BE, Richter D, Simpson T, Fonn D, Doughty $\mathrm{M}$, Gordon K. CANDEES. The Canadian Dry Eye Epidemiology Study. Adv Exp Med Biol. 1998;438:8056.

[17]. Hay EM, Thomas E, Pal B, Hajeer A, Chambers $H$, Silman AJ. Weak association between subjective symptoms or and objective testing for dry eyes and dry mouth: results from a population based study. Ann Rheum Dis. 1998;57(1):20-4.

[18]. Schaumberg DA, Buring JE, Sullivan DA, Dana MR. Hormone replacement therapy and dry eye syndrome. JAMA. 2001;7;286(17):2114-9.

[19]. Gupta S.K., Gupta V., Joshi S., Tandon, R. Subclinically Dry Eyes in Urban Delhi: An Impact of Air Pollution? Ophthalmologica. 2002;216:368-71.

How to cite this article: Vankadara Naga Suresh, Radhika. THE PREVALENCE OF DRY EYE IN TERTIARY HEALTH CARE CENTER OF ANDHRA PRADESH. Int J Intg Med Sci 2018;5(3):592-596. DOI: 10.16965/ijims.2018.104 